\title{
Research of Teaching Optimization Strategy for Students Participation in Distance Education
}

\author{
Li Shu Ni*, Deng Ying, Han Xu \\ School of Educational Information Technology, Central China Normal University, Wuhan, China \\ Email address: \\ xlz_0820@163.com (Li Shu Ni),3078792954@qq.com (Deng Ying), 465328206@qq.com (Han Xu) \\ ${ }^{*}$ Corresponding author
}

\section{To cite this article:}

Li Shu Ni, DengYing, HanXu. Research of Teaching Optimization Strategy for Students Participation in Distance Education. Science Innovation. Vol. 8, No. 3, 2020, pp. 54-59. doi: 10.11648/j.si.20200803.11

Received: March 23, 2020; Accepted: May 26, 2020; Published: June 8, 2020

\begin{abstract}
In view of the problem that many countryside schools open not neat, bad lessons, many rural areas broadcast the high-quality teaching content in the city schools to the surrounding countryside schools through the information technologies, solving the problem of rural teaching resources, especially for music and art. In order to organize distance education better in rural school and improve the rural school students' participation, this paper takes hubei xianning center school and some of rural schools using "synchronous interaction mixed classrooms" and "synchronous interaction delivery classrooms" as examples, to collect predominantly video teaching material through field observation and interview, then has them coded qualitatively. Combined with the flow of basic elements of teaching process and teaching information among each element, this study analyzes the classroom participation of students in "synchronous interactive hybrid classroom" and "synchronous interactive delivery classroom". Finally, for the problems found, some Suggestions are put forward for the improvement of some process of the existing classroom teaching mode, so as to provide practical and effective help for the subsequent classroom development and promote the early realization of the goal of "good class".
\end{abstract}

Keywords: Synchronous Classroom, Mail Classroom, Participation, Teaching Optimization

\section{远程授课环境下对学生课堂参与度提升的教学环节优化探究— 以湖北咸宁农村教学点音乐、美术课堂为例}

\author{
李舒妮", 邓荣, 韩絮
}

华中师范大学教育信息技术学院, 武汉, 中国

\section{邮箱}

xlz_0820@163.com（李舒妮），3078792954@qq.com（邓䒯），465328206@qq.com（韩絮）

摘要：针对乡村教学点开不齐课、开不好课的顽疾, 很多乡镇地区通过信息化手段将城市中心学校优质教师的授课内 容同步直播给周边农村学校, 以解决农村教学资源匮乏的问题, 尤其针对于农村严重缺乏专业教学人员的音乐、美术 等薄弱学科。为了更好地组织与实施针对农村教学点的远程课堂教学, 提升农村教学点学生参与现状, 本文以湖北咸 宁中心学校及部分农村教学点采用的“同步互动混合课堂”、“同步互动专递课堂”为例, 在实地观察、访谈的基础上， 通过对收集到的以视频为主的课堂教学材料进行质性编码分析。结合教学过程基本要素与教学信息在各要素间的流动, 本研究分析了“同步互动混合课堂”、“同步互动专递课堂”远程教学模式在应用过程中学生的课堂参与度的情况。最后 针对课堂参与存在的问题, 对现有课堂教学模式的部分环节提出改良建议, 以期为后续课堂开展提供切实有效的帮助, 促使“开好课”的目标早日实现。 
关键词: 同步课堂, 专递课堂, 参与度, 环节, 优化

\section{1. 引言}

习近平总书记在党的十九大报告中曾多次提到教育 公平的问题, 这是由于在城乡分割体制下, 农村教育还面 临师资力量缺乏、教学质量差等诸多难题。2010 年发布 的《国家中长期教育改革和发展规划纲要（2010-2020 年)》就明确提出, “均衡发展是义务教育的战略性任务”, 要“建立城乡一体化义务教育发展机制, 率先在县域内实 现城乡均衡发展, 逐步在更大范围内推进”[1]。

在信息技术快速发展的今天, 为了提高我国农村基础 教育质量, 湖北省积极出台政策扶持, 尝试利用信息化手 段解决乡村教学点开不齐课、开不好课的顽疾, 在咸宁市 咸安区、崇阳县等地教学点采用“同步互动混合课堂”、“同 步互动专递课堂” 等教学模式, 而这种教学模式能否提高 学生参与度也是大家重点关注的问题。

\section{1. 名词解释}

\subsection{1. 同步互动混合课堂}

同步互动混合课堂教学是利用网络和远程教育媒体, 将传统的面对面教学和线上网络课结合使用, 使中心校主 讲教师所在的“本地课堂”与教学点辅助教师所在的“直播 课堂”之间实施全程同步课堂教学实况的输送, 并实现本 地课堂与异地课堂师生、生生之间的交流, 真正促进优质 教育教学资源共享的一种教学形式[2]。

中心学校主讲教师不仅要关注中心学校课堂的教学, 更要关注下辖教学点的教学; 不仅要和中心学校学生互动, 更要通过同步网络同教学点的学生密切交流, 做到上下统 一、步调一致。农村教学点教师需要转换角色, 与中心学 校主讲教师密切配合, 当好同步互动混合课堂的助教, 具 体负责教学点学生课前预习、课堂秩序维护、课堂效果反 馈和课后作业批改 [3]。同步互动混合课堂既减轻了农村教 学点的工作量, 也让教学点学生享受到中心校优质的教学 资源, 部分解决农村教学点优质资源不足的问题, 进而缩 小城乡间的教育水平差距，促进教育公平。

\subsection{2. 同步互动专递课堂}

在同步互动专递课堂教学中, 主讲教师所在的本地课 堂并没有学生, 教学对象仅仅是远端教学点的学生。一方 面, 同步互动专递课堂可以将中心校优质师资引入教学点, 并实现主讲教师与教学点学生之间的双向交互; 另一方面, 可以使主讲教师针对教学点学生的实际情况, 进行专门的 教学设计 [4], 从而能更好地照顾农村教学点学生的认知特 点、知识基础和学习需要 [3]。

在专递课堂中老师与学生都是无直接接触的, 所以在互 动时需要尽可能地发挥教师对互动过程的主导作用, 还需要 充分利用信息技术手段的优势来解决异地问题的缺陷, 在授 课的过程中要重视老师与学生之间的互动, 但是要避免形式 化的互动, 而这些的评判标准就在于学生的参与度。

\subsection{3. 参与度}

学生的课堂参与又称为课堂投入, 是课堂评价的一个重 要指标。研究表明, 学生的课堂参与既有量的差异一一参与 程度的差异, 更有质的差异一一参与性质的差异 [5]。教学中 学生的主体地位可以通过学生的参与程度, 也就是参与的量 体现出来, 学生参与教学中的数量、积极性是衡量主体地位 发挥的重要标志。本篇论文从参与的行为、参与的人数、参 与的态度这三方面来评判学生的参与程度。

参与课堂的行为包含对正在进行的教学活动给予注 视、倾听、讨论、动手练习等行为 $[6]$ 。参与的人数指在某 个环节或者活动中参与的人数和整体人数的比例情况。参 与的态度指的是学生在参与教学活动过程中所表现出来 的积极、好奇、认真、愉快等情绪体验, 基于此我们可以 大致判断出学生在课堂中的参与态度。

\subsection{4. 方法}

本研究采取的是基于编码的质性研究方法。与实证研 究不同, 质性研究的研究问题是在复杂的环境中依据研究 主题而制定的, 并且对人物、地点和谈话有丰富的描述。 在教育方面。定性研究通常被称为自然主义, 因为研究人 员经常去他或她所感兴趣的事件自然发生的地方, 只有在 行动发生的环境中观察到它, 才能最好地理解行动[7]。因 此本研究前往咸宁市咸安区、崇阳县, 在当地中心校与周 边部分农村教学点所构成的同步、专递课堂中进行了田野 调查, 通过对其实际课堂教学进行过程记录, 包括课堂视 频录制、撰写田野日志等方法进行了研究数据的收集。

对于收集到的数据, 质性研究者需要批判性地, 有知 识地一一即根据知识整合发生的认识论框架的基本假设重 新解释它们[8]。本研究选择了质性结构编码的方法对收集 到的课堂数据进行分析。在质性研究中, 编码通常是一个 单词或短语, 它象征性地为基于语言或视觉的数据分配一 个总结性、显著性、本质捕获性或唤起性属性。结构编码 是质性编码方法中的一种, 结构编码将一个基于内容或概 念的概括短语应用于与特定研究问题相关的数据片段。然 后将编码相似的片段收集在一起, 以便进行更详细的编码 和分析[9]。本文采用结构编码的数据分析方法, 以探究同 步、专递课堂教学过程中学生的参与度为主要研究问题, 对课堂数据进行分析编码并从中提炼有价值的教学过程的 意义特征, 从而得出关于课堂参与度的一般性规律。

\section{2. 课堂案例编码分析}

\section{1. 同步互动混合课堂案例分析}

\subsection{1. 互动式课堂导入}

课堂导入环节是课堂的主要教学环节之一, 对于整堂 课的授课效果和学生对于这堂课的初始感受起着至关重 要的作用。尤其是对于低年段的学生来说, 能否在短时间 
内将学生的注意力吸引到课堂上, 让他们处于较为积极的 接受状态, 是一节课的基础要求 [10]。通过对我们所编码 的同步课堂案例进行分析比较, 我们发现在盘山小学的音 乐课中, 老师在上课时让屏幕上各个课堂的学生之间相互 打招呼, 并且让中心校和教学点的同学全部起立, 一起回 忆演唱上节课所教授的歌曲, 并通过动作展示吸引同学们 一起动作。

根据相关理论的分析, 在课堂开始让同学们相互打招 呼是让学生熟悉课堂环境, 因为对于同步课堂来讲, 屏幕 授课时大多数情况下屏幕上会出现两到三个班级的同学, 新奇的场景容易分散学生注意力, 尤其是对于低年龄段的 同学, 所以熟悉不同的课堂环境是第一步。其次根据对学 生年龄, 认知, 心理等方面的分析, 教师在课堂导入时通 过音乐唤起学生的兴趣, 能使学生在情感上产生愉悦从而 引起共鸣, 并且内容与教学相匹配, 营造了这节课所需要 的氛围。最后是老师通过动作带领大家一起参与, 既满足 了该年龄段学生好动和喜欢模仿的特点, 也提高了学生们 的参与感, 令课堂的氛围更加活泼。

\subsection{2. 言语引导学生参与}

课堂主体部分, 多种多样的教学行为贯穿于课堂教学 的始终, 对教学效果有着十分重要的影响, 其中课堂教学 语言是教师教学思想的一种直接体现, 它包括讲授、提问、 等待等环节, 是信息最基本的载体, 决定着教学计划实施 的成败, 影响着学生对教学内容的理解, 对教学效果和学 生参与度的影响至关重要[11]。通过我们对我们所编码的同 步课堂案例进行分析比较, 我们发现当老师在教学过程中 语言适当的停顿与学生互动, 或通过教学语言将自己和学 生代入情景之中, 比如盘山小学的美术课中, 在每个画面 出现时, 老师都会以疑问式的语气让学生回应, “我们见到 小鹿, 要向他们干什么呀? ”一定时间的停顿后, “好, 我 们和他打招呼, 小鹿你好。”学生都会有比较积极的回应和 互动, 提升学生的参与感, 让学生更好的融入这节课。

在课堂教学中, 一般说来根据语言的性质, 可将教师 的课堂语言分为反馈性、激励性、引导性、提问性、陈述 性、命令性、重复性、过渡性和追问性等 9 种类型。研 究表明, 优秀教师善于将教学知识与生活相联系, 采用追 问性、引导性和过渡性的语言教学语言, 关注有学生参与 的师生对话; 也善于使用激励性和反馈性的语言, 增强学 生的学习动机, 诱导学生参与课堂活动。在教学中, 能采 用引导性、追问性和激励性的语言, 引导学生主动掌握知 识, 而不是用命令性, 或者过多的陈述性语言讲授知识, 从而真正体现学生主体、教师主导的教学原则。

\subsection{3. 教学点教师参与}

在前面两个片段的编码中, 我们着眼于中心校老师的 教学设计和教学策略对于学生参与情况的影响, 而实际上 对于同步课堂来说, 教学点老师的辅助作用也至关重要, 尤其是对于任务布置类的课堂。由于时空的限制, 中心校 老师无法在纪律管理、小组讨论和任务完成从旁指导方面 很好地管理教学点学生, 此时教学点老师的辅助作用就至 关重要。通过我们对我们所编码的同步课堂案例进行分析
比较, 我们发现对于任务类的课堂, 如果缺少教学点教师 的辅助作用, 就会让课堂参与度变得很低。

以盘山小学的美术课为例, 中心校老师布置任务“大 胆想象梦里边都有哪些好玩有趣的东西”后学生开始创作, 中心校的教师会对她所能接触到的学生作品进行适当的 点评和指导, 但是教学点的老师多是在走来走去的巡逻, 没有出声的点评互动。由于作画时间比较长, 部分学生出 现跑神的情况, 而且在之后的讲解评价中, 参与不到中心 校老师的互动点评中, 基本不抬头。

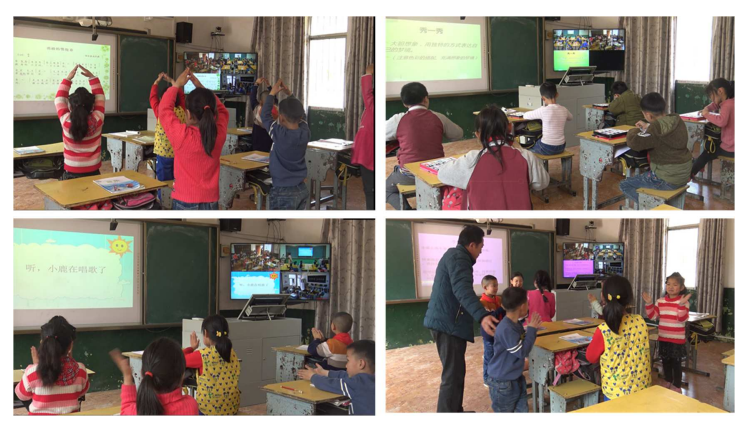

图1 教学点同步互动混合课堂学生互动、学习。

\section{2. 同步互动专递课堂案例分析}

\subsection{1. 教师关注分配}

学生的课堂参与行为和课堂情绪体验都受到教师行为 的影响[12]。在课堂中, 教师的关注行为是很重要的一类课 堂行为。当学生接受到老师的眼神、提问等方式的互动时, 容易产生受到重视的幸福感, 从而提升课堂参与的积极性。 反之, 当学生没有受到老师的注意与关注时, 学生就容易 产生学习的懈怠感。这就意味着老师的关注行为会影响学 生的心理体验和参与动机。在崇阳县实验小学的一节“画出 五味瓶”专递美术课堂中, 老师请大岭教学点的一位男生回 答思考题, 并进行了追问。在这个过程中, 只有大岭教学 点的学生抬起头, 保持注意力在老师所在的屏幕或者是回 答问题的同学身上, 而另外两个教学点——清水初小和独 石小学的学生, 有的在低头画画, 有的在和同桌聊天, 有 的在弯腰做自己的事情, 并不具有较高参与度。

专递课堂模式中一个中心校老师通常需要同时授课 几个教学点, 教师能够通过屏幕看到各个教学点学生的课 堂情况, 而各个教学点学生之间的画面是互相隔离的。当 老师在向某一个教学点的学生进行持续交流时, 关注度就 会较多的向该教学点倾斜, 其他教学点学生感受到的就是 自己失去了教师支持与关注、也就是产生“不重要、不重 视” 的情感体验, 从而失去对该教学环节的参与兴趣与动 机。

\subsection{2. 多媒体材料激发兴趣}

随着课程改革的深入, 音乐课堂教学模式越来越多元, 多媒体教学模式成为一种很普遍的教学模式, 它的优势就 是它能够通过声音、图片、文字把音乐内容很形象的表达 出来, 这是别的教学工具所达不到的一点[13]。在多媒体 的帮助下, 学生能够更直观的感受音乐, 充分调动学生的 感官系统, 激发学生学习积极性。在崇阳县实验小学专递 
音乐课的一个教学片段中, 中心校教师利用PPT向学生们 介绍彝族人民的传统服饰文化，教师准备的图片中的服饰 色彩明丽，造型丰富，一播放就引发了小学生们“哇！”的 阵阵欢呼, 体现了一种积极热烈的参与氛围, 具有良好的 展示效果。

这也印证了小学生具有活泼好动、喜欢新奇、趣味性 强的事物的特点, 生动的多媒体材料在专递课堂教学中的 使用能够使教学内容变得更有声有色, 化虚为实, 化静为 动, 从而给予学生更直观新奇的感受。教师需要根据教学 内容合适的选用多媒体资源, 使情感表达更生动形象, 符 合小学生的认知习惯, 从而激发学生的学习兴趣, 使音乐 与学生产生情感共鸣。

\subsection{3. 游戏促进参与}

小学生们具有好动的特点, 他们不喜欢在一个地方一 动不动地呆着, 他们喜欢让自己活动起来。教师应该利用 小学生们的这个特点, 在音乐教学中结合小学生们的表演 环节。让小学生们在音乐中进行舞蹈、表演, 让他们一边 唱, 一边进行表演。这样, 就充分满足了小学生们的好动 心理, 同时也调动了小学生们学习音乐的积极性[14]。

在崇阳县实验小学专递课堂音乐课一教学片段中, 老 师在讲解完舞蹈的分解动作后, 播放音乐带领学生跳彝族 舞蹈。老师边跳边讲, 学生跟着老师认真学习。在跳完两 遍后, 老师准备结束本节课程, 而在课程另一端的教学点 的学生却不愿意坐下, 一起站在座位上兴奋向老师要求: “再跳一遍！再跳一遍！”, 班级气氛兴奋而又热烈, 最终 老师只好再带领学生跳了两遍后才下课。这个片段就充分 体现了能够动起来的课堂活动在提升学生参与度方面的 显著作用。

还有一些其他类型的课堂活动比如音乐剧、击鼓传花 等, 具有创新性, 和片段中的舞蹈教学一样在课堂中能够 改变学生传统的以静为主的单调枯燥的学习方式, 可发动 全体学生主动参与、主动思考, 将课堂的主体更大限度地 还给学生, 帮助学生更充分的感受知识的魅力。
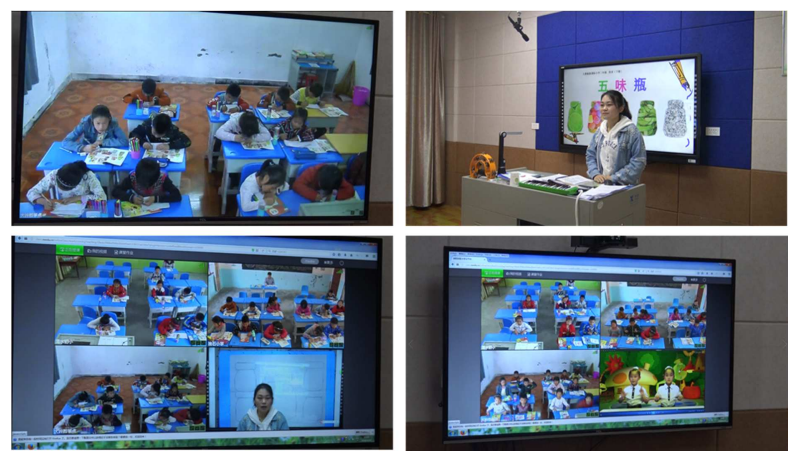

图2 中心校区同步互动专递课堂教师上课、显示屏。

\section{3. 结论与建议}

\section{1. 课堂导入转换思维}

课堂导入环节是教学的重要环节之一, 尤其是对于远 程教学的课堂来说, 老师与学生处于异地面授, 能否短时
间将学生的注意力吸引到课堂上是一节课的基础环节。通 常来讲在导入部分要注意两部分的内容, 一方面是内在目 的,即要引起学生的注意、激发学习的兴趣、引起学习的 动机、明确学习的目的建立知识间的联系; 另一方面是表 现目的,即要使学生和教师以较好的状态及时地进人课堂 教学的情境、进人课堂教学的角色 [15]。

对于同步互动混合课堂和同步专递混合课堂来讲, 在 导入环节可以注意的几点有: (1)学生之间、同学与老师之 间通过屏幕相互打招呼, 熟悉课堂情况、适应屏幕教师教 学。(2)根据课堂内容设置导入活动, 尽量可以让学生有行 动和言语上的双重配合, 这样会让学生更好的进入状态。 (3)教师通过学生的学习动机、认知结构与认知风格, 选择 适当的媒体形式与确定所要创设的问题情境, 比如音乐更 利于渲染某种气氛。(4)可以让各个教学点的学生有竞争意 识以及被关注的意识, 将有可能导致学生分神的环境转化 为不同视角督促学生参与表现的环境。

\section{2. 教学语言导引互动}

教师向学生授业解惑以及学生理解和接受的知识都 主要来自教师的语言, 课堂教学语言是教师在课堂教学中 向学生传递信息的核心手段, 让师生间有效地进行信息的 传递、情感的交流和沟通、完成教学任务、实现教学目标 [16]。

通过上文中编码片段的语言分析和相关知识的总结， 我们可以注意以下几点: (1)注重教学语言的使用并总体上 以询问式语言, 询问式语言就是以教师的意见或想法为基 础, 询问学生有关内容或步骤, 期待学生会回答接受。(2) 教师注意表情式语言的使用, 表情式语言是指接受或利用 学生的想法, 澄清适当扩大或发展学生所提出的意见或想 法。(3)善于用教学语言引导学生思考并给予学生鼓励。

\section{3. 教学点教师承担辅助职责}

在同步互动混合课堂的异地教学点和同步专递混合 课堂中, 由于师生空间分离的教学方式增强了学生在教学 过程中的自主性, 也意味着主讲教师对这些学生学习行为 的控制力大为减弱。在正常的教学环境下中心点的主讲教 师可以通过语言来引导学生互动, 而对于一些任务驱动类 的课堂, 为了能更好地维持异地课堂的正常教学秩序, 农 村教学点教师的辅助教学职责很重要[17]。如: 第二部分 提到的, 在学生完成绘画任务时, 由于时空限制中心点教 师无法概览全局, 教学点教师应该在自己班级中解答疑惑 以及辅助展示; 在中心点教师点评时还在忙自己的事情, 那教学点的老师就可以通过语言或行为的提醒让学生将 注意力放在中心点教师身上。

辅助教师一般不承担具体的知识讲授任务, 只承担异 地课堂的组织、管理与协调等辅助性工作。可以注意以下 几点: (1)课堂教学实施前明确教学前需要做的准备工作, 与教学过程中需要注意的一些事项。(2)对课堂的教学秩序 进行组织与管理, 帮助主讲教师营造良好的课堂教学氛围 与教学秩序。(3)配合中心点主讲教师处理教学过程中开展 跨课堂的互动与协作学习活动, 让学生更好的参与进来。 


\section{4. 教师均匀分配对不同教学空间教学情况的关注}

同步、专递课堂模式本身作为一种远程网络授课模式, 解决了跨越不同地区教学资源分配不均的问题, 但其教学 过程也同时受到师生物理空间分散的影响。当学生处在不 同的物理空间时, 彼此之间很难形成一种统一的集体概念, 因此教师对教学点关注的不均匀分配, 很容易造成部分教 学点学生心理失衡, 觉得自己不受到老师的重视。

为了避免此类问题, 中心校教师在教学中, 可以尽量 注意: (1)均匀分配对不同教学点学生学习状态的变化的关 注度, 适时给予一定支持与鼓励, 帮助教学点学生克服师 生空间分离的不适应感。(2)在提问、互动的环节, 当各个 教学空间学生都有较高参与热情的情况时, 教师要有意识 地对问题尽可能地进行平均分配, 保证各个教学空间的学 生都能够有较高的参与程度。(3)在同步互动混合课堂中, 当农村教学点学生的参与度明显不足时, 教师要能够及时 给予更多言语鼓励, 帮助提升学习参与。

\section{5. 利用多媒体设备开展丰富的教学活动}

现代多媒体技术在教学中的应用为课堂教学提供了 丰富的多媒体教学设备, 如电子白板、投影仪等等。同步、 专递教师可以借助配备的网络多媒体设备, 依据教学内容 选择合适恰当的图片、音乐、视频等多媒体素材资源, 创 造更生动形象的教学情境, 满足小学生的好奇心和探索欲。 同时多媒体素材的使用可以增进学生对事物的认知和理 解, 减少小学生对一些抽象的、未知的事物的认知压力, 对提升学生参与的效果和积极性有一定的帮助。

教师可以通过网络搜索等方式获取多媒体课程资源, 并将其合理应用到课前导入、课中知识讲解以及课后拓展 等环节中来。在使用多媒体进行教学的过程中, 教师需要 注意以下几点: (1)遵循认知过程, 精心设计教学内容和教 学过程、合理组织教学材料。(2)创造情景, 引导学生主动 建构知识。(3)突出培养学生的创新意识和能力 [18]。

\section{6. 游戏互动拉近师生、生生距离}

活泼好动、喜欢参与游戏活动是每个孩子的天性, 在远 程教学过程中需要能够充分考虑到小学生的性格特点, 将小 学生爱玩游戏的天性与教学内容进行有效结合, 设置创新游 戏环节, 拉近各个教学空间学生之间的距离, 提升课堂适应 感和参与度。比如: (1)针对小学音乐同步互动混合、专递课 堂, 老师可以根据课程内容合理组织安排学生学习舞蹈、音 乐剧, 可以更直接全面地感受音乐节奏的鬼未力。(2)针对小学 美术同步互动混合、专递课堂, 可以采用手指舞、你画我猜 等游戏方式进行师生、生生之间的交流互动。(3)一定的游戏 竞争也可以提升学生的课堂参与性。教师可以采用积分制的 方法吸引不同教学空间学生之间的主动参与课堂教学, 但是 教师也一定要注意保持不同教学地点的学生之间的积分差 距不能太大，避免打消学生参与积极性。

\section{4. 技术问题与期望}

在对教学视频进行分析编码时, 我们发现有些环节并非 是由于教学活动设计导致学生不参与, 而是由于设备的缺失
或没有恰当使用造成。比如在同步课堂的美术课上的作品展 示环节, 中心校老师让教室内的学生介绍自己的作品并给予 点评, 从教学点盘山小学的同学视角几乎看不到所展示的作 品, 而电子白板上还是孤零零的展示着这节课布置的任务。 假设学校在有投影仪这一设备的情况下, 老师将要介绍的作 品通过投影仪投影到白板上就能很好地解决这一问题。

教学视频中呈现出的一个的问题就是时延导致课堂 不同步, 对于同步课堂影响比较明显, 比如在盘山小学的 音乐课上, 老师就不断地在强调时延的问题。当然这类问 题我们现在还无法解决, 但是随着 $5 \mathrm{G}$ 时代的到来, 信息通 信的时延将大大减小, 这不仅仅可以用在交流通信和无人 驾驶的汽车行业, 也可以在教育中, 通过技术的飞速发展 让教育也更好的发展。

\section{参考文献}

[1] 国家中长期教育改革和发展规划纲要 (2010-2020 年) [Z], (2010-7-29) [2015-6-12]。

[2] 王继新.“互联网+”教学点: 新城镇化进程中的义务教育均 衡发展实践[J].中国电化教育, 2016.1。

[3] 付卫东, 王继新, 左明章. 信息化助推农村教学点发展的 成效、问题及对策 $[\mathrm{J}]$. 华中师范大学学报 (人文社会科学 版），2016，55（5）。

[4] 王继新. 互联网+教学点: 县域基础教育均衡发展实践 $[\mathrm{J}]$. 中国教师 教育现代化背景下的教师队伍建设专题, 2017.10。

[5] 曾琦. 小学生课堂参与结构及特点的研究[J]. 心理科学, 2001, 24。

[6] 李莉. 教师课堂教学行为与学生课堂参与的关系 [J].教学研 究, 2010, 33。

[7] Robert C. Bogdan, Sari Knopp Biklen. Qualitative research for education [M]. America:Pearson Education, 2007。

[8] P. Twining et al. Some guidance on conducting and reporting qualitative studies [J]. Computer \& Education,2017。

[9] Johnny Saldaha. The Coding Manual for Qualitative Researchers [M]. UK: SAGE Publications Ltd, 2013。

[10] 董斐娜, 吴慧聪. 课堂教学导入环节优化设计究 [J]. 岳阳 职业技术学院学报, 2014.01。

[11］刘慧敏. 教师语言艺术 $[J]$.科技信息，2009.22。

[12] 边玉芳. 教师教育教学行为对学生课堂情绪体验和参与表 现的影响[C].第十一届全国心理学学术会议, 2007。

[13] Ayers, Lydia. A multimedia approach to teaching music [C]. HKUST, 2001。

[14] 吴倩.小学音乐课教学方法浅谈 [J].北方音乐, 2014, (5)。

[15] 肖荣 黄去新 车云霞. 论课堂导入及其设计 [J]. 天津市教科 院学报, 2001.02.010。 
[16] 李如密. 中学课堂教学艺术论纲 [J]. 高等教育出版社, 2012.09.027。

[17] 雷励华 左明章. 面向农村教学点的同步互动混合课堂教 学模式研究 [J].网络教育与远程教育, 2015.11.006。
[18] 焦林. 多媒体教学的特点及教学原则和方法 [J]. 贵州民族 学院学报(哲学社会科学版), 2003, (3)。 